\title{
A internacionalização do conhecimento científico e tecnológico e seus efeitos nos Institutos Públicos de Pesquisa
}

\author{
Thales Haddad Novaes de Andrade \\ Lucas Rodrigo da Silva
}

\section{SciELO Books / SciELO Livros / SciELO Libros}

ANDRADE, THN., and SILVA, LR. A internacionalização do conhecimento científico e tecnológico e seus efeitos nos Institutos Públicos de Pesquisa. In HAYASHI, MCPI., SOUSA, CM., and ROTHBERG, D., orgs. Apropriação social da ciência e da tecnologia: contribuições para uma agenda [online]. Campina Grande: EDUEPB, 2011. pp. 281-316. ISBN 978-85-7879-187-2. Available from SciELO Books <http://books.scielo.org>.

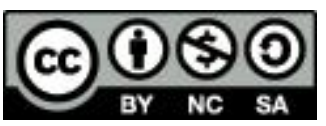

All the contents of this work, except where otherwise noted, is licensed under a Creative Commons Attribution-Non Commercial-ShareAlike 3.0 Unported.

Todo o conteúdo deste trabalho, exceto quando houver ressalva, é publicado sob a licença Creative Commons Atribuição Uso Não Comercial - Partilha nos Mesmos Termos 3.0 Não adaptada.

Todo el contenido de esta obra, excepto donde se indique lo contrario, está bajo licencia de la licencia Creative Commons Reconocimento-NoComercial-CompartirIgual 3.0 Unported. 


\section{A internacionalização do conhecimento científico e tecnológico e seus efeitos nos Institutos Públicos de Pesquisa}

Thales Haddad Novaes de Andrade Lucas Rodrigo da Silva

\section{Introdução}

A globalização e a internacionalização do campo científico representam tendências que têm afetado fortemente a constituição dos grupos sociais que conduzem a prática tecnológica em âmbito mundial. Hoje é possível detectar processos globais de articulação de empresas, laboratórios e instituições públicas de pesquisa criando uma ciência e tecnologia ao mesmo tempo desenraizada e assimétrica (GINGRAS, 2002; VESSURI, 2008).

A questão que se coloca atualmente para os países periféricos é a seguinte: como a internacionalização da pesquisa 
científica tem impactado as instituições nacionais? Como vêm sendo recrutados e fomentados os grupos que avaliam e monitoram os investimentos em projetos científicos e tecnológicos, e mediante quais critérios?

Nesse novo cenário, a conformação de um novo tipo de ciência estabelece um acordo entre a comunidade de pesquisa e os interesses do mercado. O intuito deste texto é verificar como essas tendências estão impactando na produção científica e tecnológica dos Institutos Públicos de Pesquisa, tomando como base empírica o caso do Instituto de Pesquisas Tecnológicas (IPT) vinculado a USP.

A questão da internacionalização da ciência e da consolidação de novas tendências organizacionais tem sido destaque nos estudos sociais durante os últimos anos. As transformações são sentidas através das mudanças das figuras jurídicas, de agentes científicos, além de todo um complexo de modificações que atingem ao âmago das estruturais sociais e científicas envolvidas. Os aportes sociológicos agem, para a compreensão destas questões, através de um movimento em que se busca enxergar o contexto e o conteúdo social das práticas científicas e tecnológicas, desenvolvendo um esforço compreensivo no sentido de refletir o que caracteriza a ciência e tecnologia na atualidade.

Para elucidar essas questões, parte-se para um estudo de caso sobre o Instituto de Pesquisas Tecnológicas (IPT) vinculado à USP, em que a partir deste se pretende analisar como políticas de inovação estão interferindo no critério organizacional do Instituto e da produção científica originada deste e, como estão se posicionando os 
técnicos e pesquisadores deste, no que tange as novas políticas de inovação. Partindo de um debate sobre as lógicas organizacionais, pode-se observar, ao longo do tempo, as transformações ocorridas nos IPPs (SALLES-FILHO, 2000). Essas transformações organizacionais se deram a partir de transformações econômicas, políticas e sociais que levam à consolidação de uma cultura de inovação que articule a sinergia entre Estado, economia e universidades.

Essa instituição tradicional, geradora de um conhecimento reconhecido em âmbito nacional em diferentes áreas, vem incorporando novas regras de financiamento e compartilhamento de recursos científicos e tecnológicos, e fornece subsídios interessantes para se compreender as tendências em curso. Nos últimos anos, parte da receita da instituição vem de contratos de prestação de serviços e de convênios pontuais, o que pode comprovar que a privatização da prática científica e tecnológica vem se consolidando nos institutos públicos de pesquisa em novas bases.

Em um primeiro momento, será discutida a relação entre o processo de globalização e a dinâmica científica, que sofreu grandes transformações nas últimas décadas e traz a marca da internacionalização das instituições científicas. Na sequência, será discutido um aspecto relevante nesse debate, que consiste nas formas de avaliação científica que vem se consolidando em diversas esferas, e que impacta diretamente nas conformações das instituições de pesquisa.

Depois o texto entrará na discussão dos IPPs brasileiros, procurando salientar as modificações históricas que vêm sofrendo e como isso significa, em certa medida, a adesão a tendências que se processam em escala internacional. E 
por fim, será brevemente discutido o caso do Instituto de Pesquisas Tecnológicas (IPT), da USP, que representa um exemplo ilustrativo da internalização de novas práticas científicas em nossos IPPs.

\section{Globalização e ciência}

A análise de David Noble (1987) sobre o desenvolvimento tecnológico norte-americano mostra as profundas conexões entre sistema econômico, cultura científica e prática tecnológica. Para Noble, nos Estados Unidos, a partir do século XIX, deu-se o início da formação de um grande complexo científico-militar-corporativo, cuja coerência interna foi paulatinamente se fortalecendo. A irradiação posterior desse modelo para outros países e a internacionalização das áreas de Pesquisa e Desenvolvimento levaram a uma grande alteração na articulação entre ciência, tecnologia e práticas de inovação.

Os setores elétricos e químicos formaram a vanguarda desse processo, ao articularem sinergicamente, no século XIX, diversos setores industriais e científicos antes dispersos. Principalmente os engenheiros elétricos e químicos se tornaram a elite desse desenvolvimento tecnológico ao conseguirem ocupar postos altamente relevantes em diferentes instituições estratégicas: universidades, escolas técnicas, associações científicas e direção de empresas privadas.

Essa capacidade especial de posicionamento fez com que um determinado tipo de conhecimento alçasse a uma condição privilegiada em importantes ramos industriais, influindo decisivamente na área de administração das 
empresas, no planejamento da pesquisa universitária e no currículo de formação dos cursos de graduação da área tecnológica, principalmente as engenharias.

... os engenheiros com formação científica, absorvidos pelas grandes sociedades anônimas, fundiram os imperativos do capitalismo monopolista e a tecnologia moderna em um sistema formal. A administração moderna das empresas, que representava na engenharia um deslocamento do centro de atenção do reino natural ao social, das forças produtivas para as relações sociais, constituía um intento deliberado de aliviar a tensão entre os dois, fazendo com que ambos se encaixassem dentro dos limites do capitalismo monopolista. (NOBLE, 1987, p.27).

Essa sistematização de atividades envolvendo administração racional de empresas, educação técnica, profissionalização e participação em associações científicas possibilitaram a determinados ramos da área de engenharia controlar a estruturação de um campo altamente hierarquizado e estratégico, conciliando interesses econômicos, administrativos e científicos para o favorecimento do capital monopolista.

A engenharia assume uma posição de liderança incontestável, passando a difundir seus valores científicos e sua concepção tecnológica para os diferentes ramos da economia. Os comportamentos de agências estatais, empresas e universidades apontam para uma convergência de interesses entre elites anteriormente dispersas. 
Um processo semelhante ocorreria, no Brasil, ao longo do século XX, mas com a diferença de que as lideranças da área de engenharia eram extremamente dependentes em termos políticos e de recursos frente à burocracia estatal, o que as impedia de veicular seus valores com o mesmo ímpeto verificado nos países centrais (KAWAMURA, 1981).

Na passagem do século XIX para oXX, fazia-se necessário estruturar os grandes impérios industriais recém-inaugurados com um aporte ao mesmo tempo administrativo e técnico. Para isso, era fundamental assegurar espaço para uma camada privilegiada de funcionários fortemente equipados com essas duas características.

Esses grupos profissionais foram responsáveis por sistematizar e quantificar as operações de importantes grupos empresariais, aprimorando os métodos de contabilidade, previsão de investimentos e processamento de dados estatísticos para diferentes finalidades.

A hierarquização de funções e as formas de comunicação intersetoriais foram também estabelecidas mediante a padronização de procedimentos e a monopolização de conhecimentos técnicos e de ferramentas administrativas na mão de uma elite qualificada de engenheiros bem situados nos conglomerados americanos, e que posteriormente irradiaram seus pressupostos e procedimentos para instituições corporativas e científicas espalhadas por diferentes países.

Após a segunda guerra mundial, é possível perceber uma radicalização dessas tendências e a entrada em cena de outros agentes. Ocorreu um grande crescimento da participação militar e dos setores públicos no financiamento da ciência e da inovação tecnológica. 
A participação do Estado americano no estabelecimento da agenda tecnológica promoveu o fortalecimento de uma elite formada dentro dos cânones da engenharia elétrica e levou à articulação de setores antes dispersos, como biofísica, bioquímica e outras áreas de fronteira (VELHO, 2008).

$\mathrm{Na}$ América Latina, instituições americanas foram fundamentais para o desenvolvimento de áreas científicas estratégicas. Desde o início do século XX, a Fundação Rockfeller viabilizou o treinamento e formação de quadros na área de saúde, interagindo fortemente com instituições nacionais e enviando profissionais para se capacitarem no exterior (FARIA, 2007).

A filantropia científica americana, atrelada ao impulso modernizador de nossas elites nas primeiras décadas, aponta para um caso bem sucedido de articulação internacional que viabilizou o desenvolvimento de um projeto inovador de política sanitária em um país subdesenvolvido e ainda atrelado a um modo de vida tradicional em termos institucionais.

A globalização da economia, que começou a ser percebida principalmente nos anos 80, teve um impacto acentuado na reconfiguração desses grupos dominantes em termos científicos e tecnológicos (HUMBERT, 2005).

As empresas que lideram determinadas áreas, como indústrias químicas ou farmacêuticas, passam a investir intensivamente em tecnologia e estabelecem redes que cruzam as fronteiras nacionais, compartilhando conhecimentos e formas de atuação em diferentes continentes. 
Estes grupos começaram a adotar uma articulação cada vez mais sinérgica e complementar, estabelecendo um diálogo mais próximo e eficiente entre centros produtores e consumidores de tecnologia. Essa diferenciação inclusive deixou de ser tão nítida, pois produtores e consumidores acabam por se articular em termos de um crescente compartilhamento de conhecimento tecnológico devido ao comportamento reticular das grandes companhias.

Humbert (2005) aponta que, nas últimas décadas, deu-se uma grande transformação da política científica e tecnológica das grandes empresas, o que tem gerado uma presença maior de atividades relevantes em firmas situadas em locais menos privilegiados.

Muitos autores enfatizavam que as multinacionaisestavam transferindotecnologias obsoletas ou tecnologias muito atrás da fronteira tecnológica e que a transferência não era completa e geralmente era superfaturada. A globalização da tecnologia abriu as "caixas": as tecnologias são cada vez menos adaptadas a um contexto único e as multinacionais não relutam mais em conduzir a P\&D no exterior, não apenas em países industrializados, mas também em países menos desenvolvidos... graças também à descentralização permitida pelo desenvolvimento das TICs [Tecnologias de Informação e Comunicação]. (HUMBERT, 2005, p.275).

Em outras palavras, as elites científicas presentes nos países centrais passaram a estabelecer um diálogo cada vez mais próximo com grupos dominantes de países periféricos, através de difusão de conhecimentos em laboratórios 
integrados tecnologicamente, compartilhamento de patentes e insumos.

O desenvolvimento de projetos de produtos com potencial para alcance mundial, as disputas internas as grandes empresas em processos de licitação para exploração de produtos tecnológicos e o crescimento dos índices de escolarização em diferentes regiões do planeta viabilizam esse compartilhamento de oportunidades, formação de grupos privilegiados em centros diversificados e descentralização decisória.

Passou a ocorrer em grandes empresas transnacionais o que alguns analistas chamam de diversificação tecnológica, uma nova forma de integração de conhecimento e das oportunidades de desenvolvimento de projetos. Segundo a análise de Gomes (2003),

A diversificação tecnológica passou a ser uma importante característica das ETNs [Empresas Transnacionais], na medida em que as subsidiárias no estrangeiro têm assumido papéis específicos nas funções de P\&D, seja na ênfase continuada ao processo local de inovação, seja no desenvolvimento de um capital organizacional que permite que as ETNs integrem as atividades tecnológicas das unidades dispersas. A crescente dispersão geográfica dos ativos estratégicos impulsiona a capacitação das filiais no estrangeiro, tanto em relação ao crescimento horizontal, das comunicações interfronteiras nacionais, quanto no sentido vertical, de utilização sistemática do conhecimento tecnológico das diversas bases da organização. Por isso, o objeto das pesquisas tem crescentemente 
se movido dos benefícios estratégicos da utilização de recursos emergentes de uma subsidiária estrangeira particular em direção às vantagens associadas à contínua integração... as tecnologias de informação permitiram que as subsidiárias no país se integrassem aos laboratórios centrais das ETNs, dando-lhes condições de desenvolver e participar de outras atividades tecnológicas, além das tradicionais funções de adaptação de processo e de produtos. (GOMES, 2003, p.268)

A ampla literatura sobre o processo de internacionalização de $\mathrm{P} \& \mathrm{D}$, que aponta para a existência de diversas estratégias corporativas para o desenvolvimento científico e tecnológico em regiões diversificadas, detecta a existência de um conjunto de valores comuns que atravessam os diferentes níveis de influência desses setores.

A análise de Albert; Laberge (2007) indica que os formuladores de políticas tecnológicas no Canadá e Quebéc seguem parâmetros de economia e inovação gestados em outros centros, perfazendo uma situação de disseminação internacional de perspectivas científicas e tecnológicas. Os setores locais que não compartilham das premissas do Sistema de Inovação e não seguem os procedimentos ligados a essa concepção, acabam sendo negligenciados e não usufruem de boas condições de trabalho e inserção profissional.

No caso brasileiro, essas tendências representaram mais recentemente uma perspectiva de renúncia ao Estado de intervir decisivamente na área de ciência e tecnologia e copiar modelos de instituições internacionais que 
prescrevem fórmulas para arranjos organizacionais das práticas científicas (BAUMGARTEN, 2008).

Em outras palavras, as análises dos autores indicam que as elites inovativas do setor público são aquelas que melhor incorporam os valores consagrados do pensamento tecnológico em escala internacional, oriundos principalmente das concepções de sistemas de inovação e arranjos produtivos locais.

\section{Avaliação da pesquisa científica e tecnológica}

O compartilhamento de procedimentos semelhantes e utilização de referenciais comuns em escala internacional podem ser percebidos claramente também no caso das metodologias de avaliação de programas científicos e tecnológicos.

Segundo Davyt; Velho (2000), o sistema de avaliação científica pelos pares, que vigorou, durante muito tempo, em agências de fomento e universidades, vem sendo substituído ou complementado por outras formas de avaliação. Segundo os autores, isso tem significado o fim de certa era de desenvolvimento científico e tecnológico e início de um processo de tomada de decisões em que outros agentes passam a ser relevantes para a definição da excelência científica.

Existem vários sinais, neste momento, que o contrato social entre ciência e Estado que originou o aparato institucional de política científica cujo processo decisório central é o sistema de revisão por pares 
- está em crise. Um novo contrato está sendo negociado. Que contrato é esse e como ele está afetando ou pode afetar os mecanismos de alocação de recursos nos organismos de financiamento à pesquisa? (DAVYT; VELHO, 2000, p.116)

A questão da utilidade do conhecimento científico está se enraizando nas discussões sobre avaliação de ciência e tecnologia, e um novo arcabouço institucional e uma nova mentalidade se impõem.

Os governos buscam, na área econômica, o suporte necessário para estabelecerem uma coerência na definição de estratégias e prioridades nas políticas científicas e tecnológicas. O controle externo da ciência e tecnologia retira dos espaços reconhecidos de atuação as diretrizes fundamentais, criando um sistema avaliativo cada vez mais uniforme e programado.

Esses estudos servem para ajustar as técnicas à realidade empresarial, e com isso promovem o fortalecimento de novas elites científicas e tecnológicas responsáveis pelo aprimoramento do ajuste sistêmico entre universo corporativo, Estado e instituições de pesquisa.

A partir dos anos 80, a implementação de políticas tecnológicas exigiu o crescimento e qualificação das atividades de Avaliação de Impactos Tecnológicos, para se prever os impactos sociais das tecnologias e concomitantemente a Avaliação de Impactos Regulatórios, de modo a se verificar a eficiência das práticas de regulação. Não é mais possível financiar projetos tecnológicos e de inovação sem incorpo- 
rar metodologias de avaliação que estabeleçam parâmetros de desempenho e eficácia dos projetos.

Agentes situados para além do círculo institucional mais próximo podem interferir nos mecanismos de seletividade dos projetos e nos ajustes a serem desenvolvidos ex ante (VELHO, 2008). Assiste-se à convergência entre as tradições de avaliação interna (revisão por pares) e externa (governo, avaliadores profissionais, órgãos de financiamento, etc.), e a emergência de uma nova gestão, que exige indicadores de desempenho e de programação das instituições de $\mathrm{P} \& \mathrm{D}$, e a busca por meios efetivos que associem tecnologia e desempenho.

De acordo com relatório da União Europeia, além da variedade metodológica de abordagens para avaliação da implementação de políticas, os "policy makers" têm que procurar inserir também outros grupos de interesse no processo avaliativo e o estabelecimento de uma agenda política mais abrangente (FAHRENKROG et al., 2002).

Nas duas últimas décadas, esses procedimentos de avaliação de impactos foram alçados à condição de elementos estratégicos na definição dos orçamentos de pesquisa, e os membros da comunidade científica precisam compartilhar espaço com agentes com interesses empresariais mais definidos. Essas iniciativas têm sido importantes na busca da padronização de comportamentos e investimentos científicos e tecnológicos, estritamente vinculados aos interesses de grupos empresariais e das principais agências e centros de pesquisa tecnológica (FAHRENKROG et al., 2002).

Um novo contrato entre ciência e sociedade está sendo construído e, nesse processo, uma nova elite adquire ampla 
coordenação, aquela situada nos redutos tecnológicos, que ganham mais espaço nas agências de avaliação e pretendem impor uma agenda científica.

(...) mais recentemente, a presença crescente da engenharia dentro da National Science Foundation (NSF), a retitulação dos Science Indicators para Science and Engineering Indicators, e a mudança na NSF de julgamento por pares a julgamento de mérito - este último misturando avaliações de mérito técnico pelos pares com assessoramentos de utilidade prática assinalam um novo ponto de balanço no equilíbrio dinâmico entre conhecimento e utilidade. (CHUBIN; HACKETT apud DAVYT; VELHO, 2000, p.115)

Em alguns países, como Reino Unido e Holanda, essas tendências estão se fazendo cada vez mais presentes, e o processo de avaliação pelos pares não dispõe do mesmo peso que tinha antes na avaliação da relevância científica.

O grande investimento realizado por diferentes governos e grupos empresariais, nas últimas décadas, para o aperfeiçoamento das fórmulas de avaliação científica em termos cientométricos e de impactos econômicos, sociais e ambientais espelha claramente a tendência da busca de uma agenda comum, capitaneada principalmente pelos grupos dominantes das agências estatais e das entidades de desenvolvimento tecnológico.

Analisando o caso do INRA francês (Instituto Nacional de Pesquisa Agrícola) enquanto campo marcado por disputas para se definir a competência técnica e científica, Bourdieu (2004) afirma que o incremento da lógica 
administrativa e gerencial do Instituto sinaliza para essas tendências administrativas em escala internacional.

O crescimento da importância dos gestores e administradores científicos tem colocado em posições contrárias dois tipos de capital científico: o capital científico puro, detido pelos especialistas em suas diversas qualificações, e o capital científico institucionalizado, controlado por instâncias de direção dos centros de pesquisa.

As técnicas organizacionais e de controle da atividade científica adquirem legitimidade ao sintonizarem seus pesquisadores aos programas institucionais de desenvolvimento, os quais são dominados por uma lógica produtivista e empresarial internacionalizada.

\section{Os IPPs no Brasil}

Nesse item, discutiremos brevemente o contexto histórico do surgimento dos IPPs no Brasil. Os IPPs (Institutos Públicos de Pesquisa) existem, no país, desde a segunda metade do século XIX, eles possuem uma trajetória dividida em cinco grandes momentos.

O primeiro momento está vinculado ao modelo primário-exportador; o segundo vinculado ao modelo de desenvolvimento com núcleo na industrialização por substituição de importação; o terceiro, no momento da Ditadura Militar; o quarto, no momento da chamada década perdida, 1980 e; por fim, o quinto momento, no cenário da redemocratização (DAGNINO; NOVAES, 2005). Os cinco momentos esboçados aqui estão representados em uma linha histórica que corresponde ao período de 1890 aos dias atuais. 
Os primeiros IPPs surgem, no Brasil, com o objetivo de responder aos problemas da sociedade, com interesses unicamente utilitaristas da ciência, são voltados para a área de saúde humana, para produção agropecuária e recursos naturais (DAGNINO; NOVAES, 2005).

Nesse primeiro momento, existia, na produção científica, uma forte aliança com a oligarquia rural e a burocracia local, que sustentava o modelo econômico primário-exportador. Seus objetivos eram de produzir conhecimentos diferenciados e levá-los para Europa.

Embora politicamente emoldurado por um Estado oligárquico, este modelo possibilitou um mecanismo de acumulação no âmbito do qual as vantagens econômicas comparativas (...) asseguravam, mesmo em condições de comércio desigual, uma renda concentrada nas mãos de uma incipiente burguesia com raízes agrárias. (DAGNINO; NOVAES, 2005, p.32)

A contribuição deste primeiro momento, com a produção de uma ciência utilitarista, está no fato desta possibilitar um alto desempenho econômico dos agentes envolvidos e propiciar, concomitante a isso, o início do processo de industrialização nacional, provocado justamente pela demanda de tecnologia das elites nacionais, viabilizando, dessa forma, o aprofundamento deste processo.

Os IPPs criados nesta dinâmica propiciaram o desenvolvimento industrial, contudo as tecnologias incrementadas bastavam em si, não havendo uma necessidade de um encadeamento produtivo. É importante lembrar que, neste 
momento, o Brasil ainda dependia quase inteiramente da tecnologia externa, com regras ainda voltadas para o pacto colonial do binômio metrópole-colônia. Esse momento permaneceu desde a segunda metade do século XIX até os anos de 1920.

O segundo momento inicia a partir de 1920 na crise do modelo agrário-exportador concomitante com o declínio do período oligárquico, no Brasil, e se estende até o final dos anos 50. É nesse momento que o desenvolvimento tem seu núcleo na industrialização por substituição de importações. Os institutos voltados para a produção de tecnologia nacional ganham força nesse período.

O segundo momento ocorre na mudança do modelo de desenvolvimento, que passa a ter seu núcleo na industrialização por substituição de importações. É quando entra em cena um novo ator: os chamados Institutos de Pesquisas Tecnológicas. (DAGNINO; NOVAES, 2005, p.33)

A década de 1920 foi de extrema importância para o Brasil, mais precisamente para o Estado de São Paulo. Pois é nesse período que se aceleram os processos de diversificação e integração industrial, principalmente nas empresas voltadas para a construção civil (GITAHY, 2001). Naquele momento, a burguesia cafeeira se mudou para os centros urbanos, gerando dessa forma maiores investimentos em construção civil, devido à demanda por moradias de alto padrão.

É nessa passagem que o modelo de industrialização por substituição de importação é cunhado. Inicialmente com o 
objetivo desses construtores em investir em tecnologia para substituir os materiais mais caros e de difícil transporte. A partir da Primeira Guerra Mundial (1914-1919), o modelo de substituição de importação ganha mais força no Brasil (GITAHY, 2001).

Nesse período, foi atribuída grande relevância para os institutos de pesquisas tecnológicas, na medida em que se aumentaram as demandas, tanto das empresas quanto dos construtores.

Concluindo, a projeção internacional em tecnologias correlatas ao cimento e ao concreto, alcançada posteriormente pelo Brasil, durante a década de 1940, decorre não apenas das dificuldades enfrentadas pelos pesquisadores europeus, durante a Segunda Guerra Mundial, mas também do trabalho acumulado do governo estadual, de escolas, instituições de pesquisa tecnológica, de empresas e de engenheiros, que, durante mais de trinta anos, construíram instituições, transferiram tecnologia, adaptaram conhecimentos produzidos no exterior às condições locais, e buscaram a inovação, mesmo enfrentando condições difíceis em momentos de crise. (GITAHY, 2001, p.687)

A contribuição deste segundo momento está no fato de que o modelo de substituição de importação concomitante a uma burguesia industrial nascente promove, não apenas demandas tecnológicas, mas também encadeamentos produtivos voltados cada vez mais por processos de sofisticação tecnológica. (DAGNINO; NOVAES, 2005) 
Contudo, o segundo momento da instauração dos IPPs no Brasil, por mais importante que tenha sido para o desenvolvimento das demandas tecnológicas, tem somente relevância no que tange ao alavancamento "quantitativo" da tecnologia, ou seja, esses IPPs produziam uma ciência adaptativa e pouca "qualitativa", de uma ciência original, ou seja, ainda nesse segundo momento, o processo de capacitação tecnológica não era o foco do desenvolvimento.

Neste momento, não há uma articulação plena entre as instituições científicas, as políticas científicas estão soltas e desarticuladas e, além disso, são subordinadas ao capital internacional (BAUMGARTEN, 2008).

O terceiro momento ocorre em meio ao Estado autoritário, entre as décadas de 1960 e 1985. Este é período de maior força em relação ao desenvolvimento tecnológico nacional, seguindo ainda no modelo da industrialização por substituição de importação, este momento tem por objetivo lançar o país numa fase mais avançada de industrialização (DAGNINO; NOVAES, 2005).

E não apenas isso, mas este também é um período de mudança (pelo menos no plano do discurso), em que há uma colocação das políticas de Ciência e Tecnologia (C\&T) numa posição mais estratégica do desenvolvimento, através, por exemplo, do I PND (Plano Nacional do Desenvolvimento) de 1972-1974 do governo Médici, que tinha por objetivo reduzir a necessidade de importação de tecnologia, dessa forma, pensar na competição industrial não acarreta pensar somente no crescimento econômico, mas também no crescimento de alta tecnologia, equiparando às condições das empresas estrangeiras. (BAUMGARTEN, 2008) 
Em 1975-1979, no governo Geisel, ocorreu a vigência do II PND, que incorporou as diretrizes propostas do plano anterior. Neste plano, a retórica foi de fato implementada. A ênfase da política industrial do Governo Geisel recaiu na indústria eletrônica de base, fundamentada em razões de segurança e defesa. Dessa forma, no momento de crise do petróleo e toda a crise de lucratividade que atingia o mundo, ocorreu um apoio cada vez maior entre as políticas industriais e as políticas de C\&T, fato muito bem articulado que resultou na criação da usina atômica de Angra do Reis. (BAUMGARTEN, 2008)

O período das décadas de 1960 e 1970 foi o de maior diversificação da ciência no Brasil, a existência de atores científicos, tais como os institutos de pesquisa tecnológicos surgidos no segundo momento e não muito bem articulados, nesse terceiro momento, eles são muito mais expressivos e concatenados, evidenciando nesse período uma clara relação entre "burocracia e tecnociência".

$\mathrm{O}$ quarto momento se caracteriza pelo processo de redemocratização, exclusivamente a década de 1980. Nesse período, são iniciados os processos de abertura econômica e política e, nesse momento, as ligações que os institutos de pesquisas tinham com o Estado se "desmancham", pois como já visto anteriormente nas décadas de 1960 e 1970, as políticas científicas foram apoiadas sistematicamente no Estado autoritário (IPT, 1999).

O ponto principal deste momento está em entender que, na década de 1980, no Brasil, que também ficou conhecida como "década perdida", a abertura para o capital estrangeiro - os ajustes neoliberais de desmonte do Estado 
- concomitante com a desvalorização do tecido produtivo local, vai ocorrer para os IPPs um processo de "desfuncionalidade", ou seja, esta abertura ao estrangeiro diminuiu consideravelmente as demandas que tradicionalmente eram exercidas para os IPPs.

O quinto e último momento nessa linha histórica da trajetória dos IPPs, no Brasil, segue da década 1990 até os dias atuais. Este momento oferece uma nova perspectiva aos IPPs. Se anteriormente estes institutos atenderam às demandas das elites econômicas, agora têm por novo objetivo atender às demandas de outros atores, recuperando seu dinamismo de habilidade de redirecionamento de suas prioridades, diferentes daquelas econômicas/produtivas.

Os IPPs, nas últimas décadas, atravessaram um profundo processo de incorporação de mecanismos de gestão e novas formas de financiamento de pesquisas (SALLES FILHO et al., 2000). São essas transformações, iniciadas nas décadas de 1980 e 1990, sendo estas referentes à reforma do Estado e de caráter político, fiscal e institucional, que se estendem aos IPPs, implementando nestes nova organização interna que responde às pressões da sociedade e ao fenômeno da globalização.

... os IPPs terão que, sob a perspectiva política, se subordinar às demandas de segmentos da sociedade civil muito mais do que às demandas advindas da lógica interna corporativa (...); fiscal, fundar uma cultura de recursos públicos... prestar contas a todos os segmentos da sociedade; e, institucional, introduzir critérios de gerência técnica e de planejamento que as aproximem das formas mais eficientes de gestão. (SALLES FILHO et al., 2000, p.29-30) 
E sob esta representação elucidada por Salles-Filho (2000) sobre o os panoramas dos IPPs perante as perspectivas políticas é que se faz necessária a apresentação do contexto histórico do Instituto de Pesquisas Tecnológicas (IPT) com o objetivo de perceber as influências do social nas relações entre este instituto e alguns programas políticos disposto na linha do tempo das transformações políticas e econômicas nacionais.

\section{0 caso do IPT}

\section{Histórico do instituto}

O IPT é uma instituição pública de pesquisa e inovação tecnológica que, nas últimas décadas, tem discutido essas tendências organizacionais e representa um exemplo interessante para o exame da questão da internacionalização do conhecimento científico.

O começo da história do IPT confunde-se com a da Escola Politécnica de São Paulo em 1899. Seu objetivo era de atender às demandas de ciência e tecnologia dos setores públicos e privados, bem como contribuir para o desenvolvimento do conhecimento científico e tecnológico (SALLES FILHO et al., 2000)

Podem-se identificar, na trajetória institucional do IPT, quatro fases distintas: laboratório vinculado à academia; consolidação como instituição independente; consolidação nas atividades principais e crise nas áreas emergentes; e uma nova forma jurídica - sociedade anônima. 
Na primeira fase institucional do IPT, que corresponde ao período de 1870 - antes mesmo da existência deste instituto - até o início da década de 1920, do laboratório vinculado à academia, representava um mecanismo de atendimento às demandas do progresso urbano (GITAHY, 2001).

O IPT inicialmente era vinculado ao Gabinete de Resistência de Materiais (GRM) com o objetivo único de esclarecer as empresas sobre a qualidade dos produtos. Na década de 1920, a demanda por tecnologia aumentou e o GRM foi substituído por um novo organismo que dava conta dos novos paradigmas da sociedade, o Laboratório de Ensaio de Materiais (LEM), ainda vinculado à Escola Politécnica. Os objetivos do LEM foram ampliados, enfatizando ensaios e pesquisas com ênfase em propriedade de produtos nacionais. O LEM foi adquirindo mais autonomia frente à Escola Politécnica, em termos financeiros e administrativos principalmente, e com isso passou a ter contornos mais nítidos enquanto instituição de pesquisa.

A segunda fase da trajetória institucional do IPT trata de sua configuração como organismo independente. Em 1934, meses antes do surgimento da Universidade de São Paulo (USP), o LEM foi transformado em Instituto de Pesquisas Tecnológicas (IPT). O instituto a partir de então tinha conselhos técnicos próprios para garantir autonomia, representado numa figura jurídica de autarquia, com patrimônio próprio, sede e foro na cidade de São Paulo. Ainda com vínculos com a Escola Politécnica, ocorre expressiva participação de empresas privadas, no que tange o financiamento (SALLES FILHO et al., 2000). 
A terceira fase da trajetória institucional é a consolidação nas atividades principais (nesse caso a construção civil) e crise nas áreas emergentes, período este representado a partir do final dos anos de 1940 até 1970.

Nesse período, ocorrem, no Brasil, dois elementos marcantes: o primeiro relacionado à política de substituição das importações num período aproximado entre as décadas de 1940 e 1960; e o segundo se refere à implementação do I Plano Nacional de Desenvolvimento (I PND) pelo regime militar (BAUMGARTEN, 2008).

Esse contexto histórico é importante, pois atinge diretamente o IPT, pois a partir dos anos de 1940, o Instituto expande sua capacidade tecnológica, atingindo outras áreas do conhecimento diferentes daquelas da construção civil.

O que mais caracteriza a atuação do IPT, de três décadas para cá, é uma intensa participação nos problemas tecnológicos e no desenvolvimento brasileiro. Na década de 50, o País passou por um grande surto de industrialização. Com a dificuldade cada vez maior de importação de matérias-primas, acelerou-se o desenvolvimento de produtos nacionais. (IPT, 1979)

Os anos do Milagre Brasileiro (1968 - 1973) foram importantes para o instituto, pois nesse período cresceu a demanda por novas obras públicas, tais como o metrô de São Paulo e a Rodovia dos Imigrantes. Com a crise do petróleo, em 1973, a demanda por tecnologias alternativas aumentou, por exemplo, a implantação do Pró-Álcool em 1975. Isso levou a que o IPT fosse sendo moldado para assimilar essas novas demandas tecnológicas. (SALLES FILHO et al., 2000) 
A partir de 1976, a lógica institucional do IPT se modifica, a quarta fase institucional é a de uma nova forma jurídica, a sociedade anônima. A transformação jurídica para sociedade anônima faz com que o Instituto passe a organizar suas atividades autonomamente, direcionando suas atenções para obtenção de recursos e o IPT pode a partir de então estabelecer relações com o mercado de forma mais organizada e eficiente (SALLES FILHO et al., 2000).

Nos anos 80, o IPT, assim como grande maioria dos IPPs nacionais, sofre um período de crise, devido à abertura ao capital internacional simultâneo ao processo de globalização.

A crise da chamada década perdida abateu-se fortemente sobre o IPT. A instituição sofreu, a partir da primeira metade da década de 80, uma série de dificuldade: diminuição nas suas dotações, reduções forçadas de quadro, suspensão de planos no interior (...). A partir da década de 1990, com a tônica dada à privatização de toda atividade econômica que acompanhou o movimento de globalização e dos reiterados cortes nas suas dotações orçamentárias, o IPT reconsiderou seu relacionamento com as empresas industriais da iniciativa privada. Em interação, com empresas, (...) o IPT está retomando sua antiga linha de atuação, que consiste em enfocar os problemas da indústria, em parceria íntima com as equipes técnicas desta. (CASTRO, 2009)

Dos anos 90 em diante, o conhecimento tecnológico passa a ser visto como importante elemento competitivo e 
o IPT usufrui de políticas de ciência e tecnologia que permitem o estabelecimento de novas parcerias com indústrias que não podem custear um departamento de $\mathrm{P} \& \mathrm{D}$ próprio. (SALLES FILHO et al., 2000; CASTRO, 2009).

Em um período de referência para o panorama político-econômico, nacional e internacional, de abertura de mercados e de aumento da competitividade internacional, o IPT, junto com empresas e governos, passa a estabelecer uma agenda de cooperação envolvendo pesquisa tecnológica e política industrial, em prol da manutenção das taxas de crescimento econômico.

\section{Novas tendências}

Ao longo do último quarto do século passado, o IPT fez a P\&D em empresas privadas e públicas, delineando um novo padrão de industrialização. É nesse período que se inicia a tônica dada à privatização de toda atividade econômica que acompanhou o movimento de globalização e dos reiterados cortes nas suas dotações orçamentárias.

Dos anos 90 em diante, o cenário político-econômico começa a se restabelecer, destacando a tecnologia como importante elemento competitivo e, nesse contexto, o IPT passa a estabelecer novas parcerias com indústrias que não podem custear um departamento de P\&D próprio.

Como um exemplo desse estabelecimento do IPT em desenvolvimento tecnológico em parceria com empresas nacionais, no período da década de 1990, podem-se destacar os acordos com indústrias de base feitas em 1995, tais como a Cia. Siderúrgica Nacional e a Cia. Brasileira 
de Metalurgia e Mineração, tendo por objetivo ampliar a capacidade tecnológica de processos produtivos destas empresas.

O IPT celebra com a Cia Siderúrgica Nacional o primeiro acordo de parceria no âmbito do programa de Inovação Tecnológica, da FAPESP. O Objetivo é o desenvolvimento de chapas de aço elétrico de média eficiência para a fabricação de motores elétricos (...). E para a Cia. Brasileira de Metalurgia e Mineração, o IPT desenvolveu um processo alternativo na fabricação do ferro-nióbio... (REVISTA IPT - Pesquisa \& Tecnologia, p.69, 2009)

Com isso, os Institutos Públicos de Pesquisa criados no Brasil foram se consolidando, ampliando suas áreas de atuação e adquirindo competências para novos desafios e o IPT incluso, neste meio, também sofre transformações, como já visto.

Durante esses cem anos (IPT), participou das diferentes fases de desenvolvimento do Brasil, realizando contribuições importantes para o progresso de industrialização do país: da construção civil na época de sua criação, às tecnologias baseadas em informática, biotecnologia e novos materiais em período recente. (SALLES FILHO et al., 2000, p.249)

O IPT adota, a partir de meados da década de 1990, uma posição mais semelhante ao de unidades de negócios, fruto do processo de reorganização institucional recente, com o 
conceito de Áreas Estratégicas de Sustentação (AES) um conceito aplicado em gestão de empresas.

As AESs não são uma nova estrutura formal, mas sim uma nova forma de organizar atividades de pesquisa e prestação de serviços, permitindo uma flexibilização da estrutura departamentalizada; incentivando os arranjos em sistemas matriciais em redes, pois podem ser formadas por pesquisadores de apenas uma unidade ou de diferentes unidades. (SALLES FILHO et al., 2000, p.266)

Com as preocupações na fragilidade financeira e na dependência do Estado, o IPT, através das AES, implementa uma nova atuação frente aos interesses do mercado e do Estado, fazendo com que o IPT se tornasse, a partir desses mecanismos de AES, mais autônomo na captação e no gerenciamento de recursos financeiros. (SALLES FILHO et al., 2000)

Destarte o IPT, como sociedade anônima, desenvolve para si mecanismos para otimizar seu gerenciamento interno voltado para autonomia institucional. As AESs são fundamentais nesse momento, pois elas possibilitam ao IPT a promoção de alianças estratégicas entre empresas públicas e privadas, diminuindo suas dependências e legitimando suas ações.

É, portanto, na década de 1990, que o Instituto diversifica seu campo de atuação, desenvolvendo pesquisa e desenvolvimento em outros setores da ciência, que não apenas os de construção civil, mas também no setor das 
ciências biomédicas, tal qual a pesquisa em plástico biodegradável e o controle de qualidade de combustíveis em cidades paulistas para a verificação de conformidades da ANP (Agência Nacional do Petróleo).

A esse desenvolvimento em projetos de pesquisa de maior valor agregado, o IPT, no Novo Milênio, traça como "missão" à produção e capacitação laboratorial que dê conta de oferecer respostas rápidas e precisas às demandas das empresas. Para tanto, o IPT cria, em 2008, o projeto "Moderniza" que tem por objetivo arrecadar 150 milhões de reais até o final de 2010 para a modernização do Instituto, além da criação de uma célula de gestão para agilizar esses trabalhos.

Até o final de 2009, anuncia-se um montante de 57 milhões que seriam investidos em importação de equipamentos e na construção de laboratórios. Parte deste dinheiro o IPT enfatiza na capacitação de Centros Tecnológicos do próprio Instituto, que visam à sustentabilidade e a preocupação com o meio ambiente, com a racionalização do consumo de energia e com melhor aproveitamento de materiais industriais.

Para ajudar a gerir esses investimentos, o IPT criou, em Julho de 2008, a "Célula de Gestão do Processo de Modernização", cuja "missão é tornar mais ágeis os processos de contratação de bens, serviços e obras" (REVISTA IPT - Pesquisa \& Tecnologia, 2009).

O investimento desses Centros Tecnológicos reflete muito da nova tendência organizacional do IPT, pois se percebe que o foco destes investimentos vai além da 
modernização dos equipamentos do Instituto, e dirige-se a respostas rápidas às demandas do mercado.

Dessa forma, pensar em modernização do IPT, no século XXI, não passa apenas pelo patamar dos equipamentos e dos laboratórios, mas passa também por todo um processo de conscientização de problemas sociais relacionados à globalização.

Esse mesmo fenômeno provoca outros impactos na produção da atividade científica no IPT, dentre eles e talvez o mais importante, seja a questão da internacionalização do conhecimento gerado através das redes de atuação.

Nos últimos anos, podem ser observadas transformações no IPT que apontam para uma sintonização para com tendências internacionais de organização científica. A relação entre agentes públicos e privados é um tema que levanta grandes debates no IPT ao passo que marca toda a estrutura de combinações internas e externas no que tange financiamento e legitimidade do mesmo.

A transição jurídica do IPT, discutida por Salles Filho et al (2000), de autarquia para S.A. fez com que o instituto passasse a ser composto por um conselho de administração. O conselho de administração é composto em boa parte por representantes do setor privado, e setores do governo. Segundo Salles Filho et al (2000), essa alteração significou uma mudança de paradigma que não foi seguida por outros IPPs o que dá ao IPT grande autonomia em torno dos projetos de captação de capital de investimento, transformando-o em uma "empresa" pública. 
O fortalecimento do conselho de administração não é apenas fruto da troca do programa jurídico, de autarquia para sociedade anônima, ele só foi de fato implementado a partir do momento em que as áreas privadas procuraram ter maior interferência no Instituto de Pesquisa modificando, inclusive, o estatuto para se criar o conselho de administração (INSTITUTO DE PESQUISAS TECNOLÓGICAS, 2009).

A saída que o IPT tem discutido, durante o ano de 2009, com propostas para 2010, está presente na elaboração de um código de ética que permita, não apenas a questão de uma avaliação profissional de conduta e produção, mas que autorize também a entrada do Instituto no mercado financeiro de New York (NY).

O código de ética é, além de outras atribuições, uma condição que permite ao IPT colocar suas ações na Bolsa de Valores de NY. Este movimento tem por objetivo alcançar, no mercado mundial, novas redes de financiamento e de pesquisa. Os objetivos do IPT para com os interesses de criar um código de ética estão, entre outros, na busca da interação com o mercado mundial e as formas de financiamento de pesquisa.

Esse movimento de articulação da produção de conhecimentos é fruto de uma tendência originada pela globalização e que transforma não só a organização do IPT, mas também todo um ambiente de produção e consumo da ciência. E para os IPPs se legitimarem nesse contexto globalizado é preciso desenvolver uma série de mecanismos que façam a "ponte" com os países criadores dessas demandas (como exemplos EUA e Japão), que dentre essas "pontes" 
estão, a criação de um código de ética que dê acesso às redes internacionais.

Como já dito anteriormente, para consagrar o sucesso dos setores industriais e tecnologicamente avançados nacionais e mantê-los competitivos no mercado científico é preciso sacramentar as novas conexões e redes que conduzem o Brasil para os grandes centros tecnológicos.

\section{Considerações finais}

A internacionalização da tecnologia, a integração de sistemas de inovação, o desenvolvimento de metodologias de avaliação tecnológica e o fortalecimento de uma administração científica nas academias e instituições de pesquisa e novas formas de financiamento atestam que há um novo quadro social e gerencial de articulação das atividades inovativas.

Os grupos que conduzem a ciência e tecnologia em escala internacional buscam criar condições para um enquadramento específico dos interesses técnicos, conformando uma elite em escala global que se autonomiza em relação aos critérios de legitimação consagrados.

Os países da América Latina, nos anos 50 e 60, não foram capazes de acompanhar o grande impulso científico e tecnológico dos países centrais, por sua vez impulsionados pelas tensões da Guerra Fria e pela corrida espacial. Naquele momento, a produção de conhecimento era mais localizada e com menor capacidade de compartilhamento, o que inviabilizava interações efetivas entre os centros de pesquisa.

A partir da globalização, há um incremento da circulação de conhecimento e a possibilidade de uma participação 
maior dos países em desenvolvimento em adentrarem nos parâmetros legítimos de consagração científica. No entanto, a agenda neoliberal inviabilizou o aporte de recursos necessários, as instituições de pesquisa estacionaram e a agenda científica de diversos países não conseguiu acompanhar os rumos das novas formas de produção de conhecimento em escala mundial.

A partir dos anos 90, as instituições de pesquisa, no Brasil, passam a internalizar determinad as formas organizacionais que as permitem se inserir na agenda internacional como agentes reputacionais. $\mathrm{O}$ caso do IPT demonstra como as IPPs brasileiras foram instadas por uma agenda internacional a modificarem sua lógica de funcionamento, incorporando novas modalidades de contratação de serviços e captação de recursos. Atuação em bolsas de valores, atendimento a demandas empresariais são indícios de novas formas de atuação marcantes no novo cenário científico privatizado.

Este estudo defende a necessidade dos cientistas sociais trabalharem com a perspectiva de entendimento das mudanças científicas como o resultado de articulações políticas que estão para além dos espaços tradicionais da prática de pesquisa, e que operam uma articulação complexa de instituições e agentes que se tornam cada vez mais relevantes. 


\section{Referências}

ALBERT, M.; LABERGE, S. The legitimation and dissemination processes of the innovation system approach - the case of the canadian and Québec science and technology policy, Science, Technology, \& Human Values, v. 32, n. 2, mar.2007, p. 221-249

BAUMGARTEN, M. Conhecimento e sustentabilidade: políticas da ciência, tecnologia e inovação no Brasil contemporâneo Porto Alegre: Ed.UFRGS/ Ed. Sulina, 2008.

BOURDIEU, P. Os usos sociais da ciência: por uma sociologia clínica do campo científico. São Paulo: Unesp, 2004.

CASTRO, A. P. Sobre a história do IPT. Disponível em: <http://www.ipt.br/institucional/organizacao/ historico/100/>. Acesso em: 24 abr. 2009.

DAGNINO, R.; NOVAES, H. T. A adequação sóciotécnica como insumo para a recuperação dos Institutos de Pesquisa. Revista Brasileira de Gestão e Desenvolvimento Regional, v. 1, n. 3, 2005.

DAVYT, A.; VELHO, L. A avaliação da ciência e a revisão por pares: passado e presente. Como será o futuro? História, Ciências, Saúde - Manguinhos, v.7, n.1, p.93116, mar.- jun. 2000.

FAHRENKROG, G. et al. RTD Evaluation Toolbox Assessing the Socio-Economic Impact of RTD-Policies, IPTS Technical Report Series, 2002. 
FARIA, L. Saúde e política :a Fundação Rockfeller e seus parceiros em São Paulo. Rio de Janeiro: Fiocruz, 2007.

GINGRAS, Y. Les formes spécifiques de l'internationalité du champ scientifique, Actes de la recherche en sciences sociales, p.2-141, 2002.

GITAHY, M. L. C. Adaptando e inovando: o Laboratório de Ensaios de Materiais da Escola Politécnica e a tecnologia do concreto em São Paulo. História, Ciências, Saúde - Manguinhos, v.7, n.3, p. 675-690, nov. 2000 - fev. 2001.

GOMES, R. O papel das subsidiárias e a internacionalização das atividades tecnológicas pelas empresas transnacionais (ETNs), Gestão e Produção, v.10, n.3, p.267-281, dez. 2003.

HUMBERT, M. Globalização e glocalização: problemas para países em desenvolvimento e implicações para políticas supranacionais, nacionais e subnacionais, In: LASTRES, $\mathrm{H}$. et al (orgs), Conhecimento, sistemas de inovação e desenvolvimento, Rio de Janeiro: UFRJ, 2005.

INSTITUTO DE PESQUISAS TECNOLÓGICAS: Estatuto. 2009.

KAWAMURA, L. Engenheiro: trabalho e ideologia, São Paulo, Ática, 1981

NOBLE, D. El diseño de Estados Unidos: la ciencia, la tecnologia y la aparicion del capitalismo monopolístico. Madrid: Ministerio del Trabajo y Seguridad Social, 1987. 
SALLES FILHO, S. et al. Ciência, tecnologia e inovação: a reorganização da pesquisa pública no Brasil. Campinas: Komedi, 2000.

VESSURI, H. "O inventamos o erramos": la ciência como idea-fuerza em América Latina. Bernal: Universidad Nacional de Quilmes, 2008. 